\title{
IMPLEMENTASI PEMBELAJARAN SEJARAH DENGAN TEKNIK KONTEKTUAL COMMUNITY UNTUK MENINGKATKAN MOTIVASI \\ DAN PRESTASI BELAJAR SISWA KELAS XII/IPS.4 SMAN 1 KERTOSONO NGANJUK
}

\author{
Sawin \\ Sekolah Menengah Atas Negeri 1 Kertosono, Indonesia
}

\begin{abstract}
Learning History in SMAN 1 Kertosono Nganjuk in its implementation still leaves various problems. The majority of learning methods so far are more emphasized on memorization which results in that students lack understanding of the uses and benefits of what has been learned and cause a decrease in student motivation. One alternative that can be used is the application of contextual learning with Community Learning techniques. With the use of this technique, it is hoped that History subjects can be easily understood and can increase student motivation and learning achievement.

Departing from the above problems, in general the problems formulated in this study are 1) How is the motivation and learning achievement of the history of class XII / IPS.4 students before applying contextual learning to the Learning Community technique? 2) How is the contextual learning implementation with the Learning Community technique in increasing motivation and learning achievement History, 3) How is the motivation and learning achievement History of class XII / IPS students.4 SMAN 1 Kertosono Nganjuk after applying contextual learning with the Learning Community technique?

This research was conducted at SMAN 1 Kertosono Nganjuk. This research is a class action research with collaborative type. This research phase follows the Kemmis and Taggart models which include planning, implementing actions, observing, and reflecting activities. Data collection techniques used are: (1) observation; (2) measurement of learning outcomes tests; and (3) documentation.

The results of the research that have been carried out that 1) Research teachers carry out pre-cycle learning by applying lecture and test methods. 2) Implementation of Contextual Learning with Community Learning Techniques on the History of Class XII / IPS.4 Student History is carried out with 3 cycles consisting of 6 meetings. During the learning process observations are carried out to determine student motivation and at the end of the cycle a final test is carried out to determine student learning outcomes. 3) Student's motivation and learning achievement towards History through contextual learning with Learning Community techniques has increased student learning motivation from preresearch by $14.29 \%$ to $17.14 \%$ in cycle I and in cycle II to $22.14 \%$. In cycle III it increased to $32.14 \%$. The increase in learning outcomes at the time of pre-study average class of 65.74 increased in the first cycle to 66.48. In cycle II it increased to 73.16 and in cycle III it increased to 82.04. Likewise the completeness of the
\end{abstract}




\section{Sawin}

class at the time of the pre cycle by $37.04 \%$ increased to $51.85 \%$ in the first cycle and increased in the second cycle to $70.37 \%$ and in the third cycle increased to $88.89 \%$.

Key words: History, Community Engineering Contextual Learning.

\section{Pendahuluan}

Pembelajaran Sejarah di sekolah, dalam pelaksanaannya masih menyisakan berbagai permasalahan yang kurang menyenangkan. Seperti halnya proses pembelajaran Sejarah saat ini masih sebatas sebagai proses penyampaian "pengetahuan tentang ilmu Sejarah". Hanya sedikit yang arahnya pada proses internalisasi kompetensi kesejarahan pada diri siswa. Hal ini dapat dilihat dari proses pembelajaran yang dilakukan guru masih berkutat pada dominan ceramah.

Salah satu alternatif yang bisa dilakukan dalam menumbuhkan motivasi belajar siswa pada pembelajaran Sejarah yaitu dengan penerapan teknik Learning Community. Teknik Learning Community merupakan suatu teknik belajar dengan bekerja sama dengan orang lain untuk menciptakan pembelajaran yang lebih baik dibanding dengan belajar sendiri. (Nurhadi, 2004, p.47)

\section{Rumusan Masalah}

1. Bagaimana motivasi dan prestasi belajar Sejarah sebelum diterapkan pembelajaran kontekstual dengan teknik Learning Community?

2. Bagaimana pelaksanaan pembelajaran kontekstual dengan teknik Learning Community dalam meningkatkan motivasi dan prestasi belajar Sejarah ?

3. Bagaimana motivasi dan prestasi belajar Sejarah setelah diterapkan pembelajaran kontekstual dengan teknik Learning Community?

\section{Tujuan Penelitian}

1. Mengetahui motivasi dan prestasi belajar Sejarah sebelum diterapkan pembelajaran kontekstual dengan teknik Learning Community.

2. Mengetahui pelaksanaan pembelajaran kontekstual dengan teknik Learning Community dalam meningkatkan motivasi dan prestasi belajar Sejarah.

3. Mengetahui motivasi dan prestasi belajar Sejarah sesudah diterapkan pembelajaran kontekstual dengan teknik Learning Community. 


\section{Kajian Pustaka}

\section{Pembelajaran Kontekstual}

\section{Pengertian Pembelajaran Kontekstual}

Pembelajaran kontekstual adalah suatu konsepsi yang membantu guru mengkaitkan isi materi pelajaran dengan keadaan dunia nyata. Pembelajaran ini memotivasi siswa untuk menghubungkan pengetahuan yang diperoleh di kelas dan penerapannya dalam kehidupan siswa sebagai anggota keluarga, sebagai warga masyarakat dan nantinya sebagai tenaga kerja.

\section{Prinsip Penerapan Pembelajaran Kontekstual}

a. Merencanakan pembelajaran sesuai dengan kewajaran perkembangan mental (depelopmentally appropriate) siswa.

b. Membentuk kelompok belajar yang saling tergantung (independent learning groups).

c. Menyediakan lingkungan yang mendukung pembelajaran mandiri (selfregulated learning).

d. Mempertimbangkan keragaman siswa (disversity of students).

e. Memperhatikan multi-intelegensi (multiple intelligences) siswa.

f. Menggunakan teknik-teknik bertanya (Questioning) untuk meningkatkan pembelajaran siswa, perkembangan pemecahan masalah, dan keterampilan berfikir tingkat tinggi.

g. Menerapkan penilaian autentik (authentic assessment).

\section{Karakteristik Pembelajaran Kontekstual}

a. Melakukan hubungan yang bermakna (making meaningful connections)

b. Melakukan kegiatan-kegiatan yang signifikan (doing significant work)

c. Belajar yang diatur sendiri (self-regulated learning)

d. Bekerja sama (collaborating)

e. Berfikir kritis dan kreatif (critical and creative)

f. Mengasuh atau memelihara pribadi siswa (nurturing the individual)

g. Mencapai standar yang tinggi (reaching high standards)

h. Menggunakan penilaian autentik (using authentic assessment) 


\section{Komponen Utama Pembelajaran Kontekstual}
a. Konstruktivisme (Constructivism)
b. Bertanya (Questioning)
c. Menemukan (Inquiry)
d. Masyarakat Belajar (Learning Community)
e. Pemodelan (Modeling)
f. Refleksi (Reflection)
g. Penilaian sebenarnya (Authentic Assessment)

\section{Keunggulan Pembelajaran Kontekstual}

Menurut Hamdani (Hamdani, 2002, p.41) pembelajaran kontekstual memiliki keunggulan dibandingkan dengan pembelajaran lainnya yaitu bahwa pembelajaran kontekstual mendorong proses pembelajaran berlangsung atas dasar permasalahan riil dunia, sehingga lebih bermakna dan memungkinkan perkembangan pemikiran tingkat tinggi.

\section{Teknik Learning Community}

\section{Pengertian Learning Community (Masyarakat Belajar)}

Teknik Learning Community adalah teknik dimana situasi belajar yang diciptakan berdasarkan konsep CTL, dimana proses dan hasil pembelajaran diperoleh dari bekerja sama dan berkolaborasi dengan orang lain.

Hasil belajar diperoleh dari sharing antar teman, antar kelompok, dan antara yang tahu ke yang belum tahu. Di ruang ini, di kelas ini, di sekitar ini dan juga yang ada di luar sana, semua adalah anggota masyarakat belajar (Sardiman, 2005, p.225).

Kata kunci dari learning community (masyarakat belajar) adalah berbicara dan berbagi pengalaman dengan orang lain, bekerja sama dengan orang lain untuk menciptakan pembelajaran yang lebih baik dibandingkan dengan belajar sendiri (Nurhadi, 2004, p.47).

Learning Community atau masyarakat belajar bisa terjadi apabila ada proses komunikasi dua arah. Hasil belajar diperoleh dari sharing antar teman, antar kelompok, dan antara yang sudah tahu ke yang belum tahu.Dua kelompok atau lebih yang terlibat dalam komunikasi pembelajaran saling 
belajar. Di dalam masyarakat belajar ini setiap orang harus bersedia untuk berbicara dan berbagi pendapat, mendengarkan pendapat orang lain dan berkolaborasi membangun pengetahuan dengan orang lain dalam kelompoknya (Roestiyah, 2001, p.4).

Dalam bukunya Nurhadi (Nurhadi, 2004, p.47-48), Learning Community atau masyarakat belajar itu mengandung arti sebagai berikut:

a) Adanya kelompok belajar yang berkomunikasi untuk berbagai gagasan dan pengalaman.

b) Ada kerjasama untuk memecahkan masalah.

c) Pada umumnya hasil kerja kelompok lebih baik hasilnya daripada kerja secara individual.

d) Ada rasa tanggung jawab kelompok, semua anggota dalam kelompok mempunyai tanggung jawab yang sama.

e) Upaya membangun motivasi belajar bagi anak yang belum mampu dapat diadakan.

f) Menciptakan situasi dan kondisi yang memungkinkan seorang anak belajar dengan anak lainnya.

g) Ada rasa tanggung jawab dan kerja sama antar anggota kelompok untuk saling memberi dan menerima.

h) Ada fasilitator/guru yang memandu proses belajar dalam kelompok.

i) Harus ada komunikasi dua arah atau multi arah.

j) Ada kemauan untuk menerima pendapat yang lebih baik.

k) Ada kesediaan untuk menghargai pendapat orang lain.

1) Tidak ada kebenaran yang hanya satu saja.

m)Dominasi siswa-siswa yang pintar perlu diperhatikan agar yang lambat/lemah bisa pula berperan.

n) Siswa bertanya kepada teman-temannya itu sudah mengandung arti learning community.

\section{Kerangka Penerapan Teknik Learning Community}

Pembelajaran di dalam kelas dengan teknik learning community, kegiatan pembelajaran dilakukan dalam kelompok-kelompok belajar : siswa 


\section{Sawin}

yang pandai mengajari yang lemah dan yang tahu memberi tahu yang belum tahu. Masyarakat belajar bisa tercipta apabila ada komunikasi dua arah. Dalam masyarakat belajar, anggota kelompok yang terlibat dalam komunikasi pembelajaran dapat saling belajar. Siswa yang terlibat dalam kegiatan masyarakat belajar memberi informasi yang diperlukan oleh teman bicaranya dan juga meminta informasi yang diperlukan dari teman bicaranya (Nurhadi, 2002, p.48).

\section{Motivasi Belajar}

\section{Pengertian Motivasi Belajar}

Motivasi belajar adalah merupakan faktor psikis yang bersifat nonintelektual. Peranannya yang khas adalah dalam hal penumbuhan gairah, merasa senang dan semangat untuk belajar. Siswa yang memiliki motivasi kuat, akan mempunyai banyak sinergi untuk melakukan kegiatan belajar (Sardiman, 2005, p.75).

\section{Fungsi Motivasi}

Dalam belajar, motivasi memegang peranan penting. Motivasi adalah sebagai pendorong siswa dalam belajar. Intensitas belajar siswa sudah barang tentu dipengaruhi oleh motivasi. Siswa yang ingin mengetahui sesuatu dari apa yang dipelajarinya adalah sebagai tujuan yang ingin siswa capai selama belajar. Karena siswa mempunyai tujuan ingin mengetahui sesuatu itulah akhirnya siswa terdorong untuk mempelajarinya (Syaiful Bahari Djamarah, 1994, p.27).

\section{Cara Menumbuhkan Motivasi}

Beberapa cara untuk menumbuhkan motivasi adalah melalui cara mengajar yang bervariasi, misalnya penggalangan informasi, memberikan stimulus baru, misalnya melalui pertanyaan-pertanyaan kepada peserta didik, memberi kesempatan peserta didik untuk menyalurkan keinginan belajarnya, menggunakan media dan alat bantu yang menarik perhatian peserta didik, seperti gambar, foto, diagram, dan sebagainya. 


\section{Prestasi Belajar Siswa}

\section{Pengertian Prestasi Belajar}

Prestasi belajar adalah hasil yang dicapai oleh siswa dalam bentuk nilai atau skor yang merupakan penilaian pengetahuan dan pengalaman terhadap ilmu yang dipelajari. Hasil belajar tiap anak tentulah tidak sama antara yang satu dengan yang lainnya, ada yang tinggi, sedang dan ada yang rendah. Hal ini dipengaruhi oleh beberapa faktor, yang pada garis besarnya dapat datang dari dalam dan dari luar yang sedang belajar.

\section{Faktor - faktor yang Mempengaruhi Prestasi Belajar}

Slameto (Slameto, 2003, p.54) mengatakan bahwa faktor-faktor yang mempengaruhi prestasi belajar :

1) Intelegensi

2) Perhatian

3) Minat

4) Bakat

5) Motivasi

6) Kematangan

7) Kesiapan

\section{Metode Penelitian}

\section{Desain dan Jenis Penelitian}

Desain penelitian yang digunakan adalah penelitian tindakan kelas yang bertujuan meningkatkan praktek pembelajaran secara berkesinambungan, yang pada dasarnya melekat pada terlaksananya misi profesional pendidikan yang diemban guru.

\section{Kehadiran Peneliti di Lapangan}

Kehadiran peneliti di lapangan sebagai instrumen kunci penelitian mutlak diperlukan karena terkait dengan desain penelitian yang dipilih adalah Penelitian Tindakan Kelas (Classroom Action Research), yaitu dengan pendekatan kualitatif jenis kolaboratif-partisipatoris. 


\section{Lokasi Penelitian}

Penelitian ini dilaksanakan di kelas XII/IPS.4 SMAN 1 Kertosono Nganjuk. Sedangkan waktu pelaksanaan penelitian akan disesuaikan dengan jam pelajaran Sejarah pada kelas yang digunakan sebagai obyek penelitian.

\section{Sumber Data dan Jenis Data}

Terkait dengan penelitian ini yang akan dijadikan sebagai sumber data adalah 28 siswa kelas XII/IPS.4. Data penelitian ini berupa hasil pengamatan, kumpulan, pencatatan lapangan, dan dokumentasi dari setiap tindakan perbaikan penggunaan pembelajaran kontekstual (Contextual Teaching and Learning) dengan teknik Learning Community pada bidang studi Sejarah. Data yang diperoleh dari penelitian tindakan ini ada yang bersifat kualitatif dan kuantitatif. Data yang bersifat kualitatif diperoleh dari: (1) dokumentasi, (2) observasi, (3) interview, sedangkan data yang bersifat kuantitatif berasal dari evaluasi, pre test dan post tes.

\section{Instrumen Penelitian}

Dalam penelitian ini kehadiran peneliti di lapangan menjadi syarat utama, peneliti mengumpulkan data-data dalam latar alamiah, dimana peneliti bertindak sebagai instrumen kunci.

\section{Teknik Pengumpulan Data}

a. Metode Observasi

b. Pengukuran test hasil belajar.

c. Metode Dokumenter

\section{Analisis Data}

Data yang bersifat kualitatif yang terdiri dari hasil observasi dan dokumentasi dianalisis secara kualitatif melalui tahap: menyederhanakan, mengklasifikasi, memfokuskan, mengorganisasi (mengaitkan gejala) secara sistematis dan logis, serta membuat abstraksi atas kesimpulan makna hasil analisis.

Sedangkan data yang dikumpulkan berupa angka atau data kuantitatif, cukup dengan menggunakan analisis deskriptif dan sajian visual. 
IMPLEMENTASI PEMBELAJARAN SEJARAH DENGAN TEKNIK

KONTEKTUAL COMMUNITY UNTUK MENINGKATKAN MOTIVASI

DAN PRESTASI BELAJAR SISWA KELAS XII/IPS.4

SMAN 1 KERTOSONO NGANJUK

\section{Hasil Penelitian}

Tabel 1. Perbandingan Motivasi, Nilai dan Ketuntasan Kelas

\begin{tabular}{|c|l|c|c|}
\hline No. & \multicolumn{1}{|c|}{ Item } & Pra Siklus & Siklus I \\
\hline 1 & Motivasi & $14.29 \%$ & $17.14 \%$ \\
\hline 2 & Rata-Rata Nilai Tes & 65.74 & 66.74 \\
\hline 3 & Ketuntasan Kelas & $37.04 \%$ & $51.85 \%$ \\
\hline
\end{tabular}

Tabel 2. Perbandingan Motivasi, Nilai dan Ketuntasan Kelas

\begin{tabular}{|c|l|c|c|}
\hline No. & \multicolumn{1}{|c|}{ Item } & Siklus I & Siklus II \\
\hline 1 & Motivasi & $17.14 \%$ & $22.14 \%$ \\
\hline 2 & Rata-Rata Nilai Tes & 66.48 & 73.16 \\
\hline 3 & Ketuntasan Kelas & $51.85 \%$ & $70.37 \%$ \\
\hline
\end{tabular}

Tabel 3. Perbandingan Motivasi, Nilai dan Ketuntasan Kelas

\begin{tabular}{|c|l|c|c|}
\hline No. & \multicolumn{1}{|c|}{ Item } & Siklus II & Siklus III \\
\hline 1 & Motivasi & $22.14 \%$ & $32.14 \%$ \\
\hline 2 & Rata-Rata Nilai Tes & 73.16 & 82.04 \\
\hline 3 & Ketuntasan Kelas & $70.37 \%$ & $88.89 \%$ \\
\hline
\end{tabular}

Tabel 4. Perbandingan Motivasi, Nilai dan Ketuntasan Kelas

\begin{tabular}{|c|l|c|c|c|c|}
\hline No. & \multicolumn{1}{|c|}{ Item } & Pra Siklus & Siklus I & Siklus II & Siklus III \\
\hline 1 & Motivasi & $14.29 \%$ & $17.14 \%$ & $22.14 \%$ & $32.14 \%$ \\
\hline 2 & $\begin{array}{l}\text { Rata-Rata Nilai } \\
\text { Tes }\end{array}$ & 65.74 & 66.48 & 73.16 & 82.04 \\
\hline 3 & Ketuntasan Kelas & $37.04 \%$ & $51.85 \%$ & $70.37 \%$ & $88.89 \%$ \\
\hline
\end{tabular}

Dengan data-data hasil penelitian yang telah dipaparkan di atas, maka terbukti bahwa aplikasi pembelajaran kontekstual dengan teknik Learning Community dapat meningkatkan motivasi dan prestasi belajar siswa terhadap materi pelajaran sejarah. 


\section{Kesimpulan Dan Saran}

\section{Kesimpulan}

1. Sebelum tindakan dilaksanakan, terlebih dahulu guru peneliti mengadakan pembelajaran dengan menggunakan pembelajaran tradisional yaitu dengan metode ceramah dan tes. Dari hasil evaluasi didapatkan nilai rata-rata kelas sebesar 65.74 dan tingkat ketuntasan belajar mencapai $37.04 \%$ serta prosentase nilai observasi motivasi sebesar $14.29 \%$

2. Pelaksanaan Pembelajaran Kontekstual dengan Teknik Learning Community pada mata pelajaran Belajar Sejarah Siswa Kelas XII/IPS.4 SMAN 1 Kertosono Nganjuk dilaksanakan dengan 3 siklus dan masing-masing siklus terdiri dari 2 pertemuan. Selama pembelajaran berlangsung dilaksanakan observasi untuk mengetahui motivasi belajar siswa dan di akhir siklus dilaksanakan tes akhir untuk mengetahui hasil belajar siswa.

3. Secara keseluruhan, peningkatan motivasi dan prestasi belajar siswa terhadap materi Sejarah melalui pembelajaran kontekstual dengan teknik Learning Community adalah sebagai berikut, peningkatan motivasi belajar siswa dari pra penelitian sebesar $14.29 \%$ menjadi $17.14 \%$ pada siklus I dan pada siklus II menjadi sebesar22.14 \%. Pada siklus III meningkat menjadi sebesar $32.14 \%$. Peningkatan hasil belajar pada saat pra penelitian rata-rata kelas sebesar 65.74 meningkat pada siklus I menjadi 66.48. Pada siklus II meningkat menjadi 73.16 dan pada siklus III meningkat ,menjadi 82.04. Begitu juga ketuntasan kelas pada saat pra siklus sebesar $37.04 \%$ meningkat menjadi $51.85 \%$ pada siklus I dan meningkat pada siklus II menjadi $70.37 \%$ dan pada siklus III meningkat menjadi $88.89 \%$

\section{Saran}

1. Diharapkan dapat menjadi bahan pertimbangan bagi beberapa pihak, antara lain:

a. Kepala Lembaga Pendidikan/Kepala Sekolah

Alangkah baiknya jika hasil penelitian ini dijadikan pedoman oleh lembaga pendidikan untuk selalu meningkatkan motivasi dan prestasi 
belajar siswa, sebab untuk mencapai prestasi belajar siswa secara maksimal perlu adanya motivasi yang tinggi dari siswa itu sendiri.

b. Bagi Guru

Evaluasi terhadap pembelajaran kontekstual dengan teknik Learning Community seperti yang disebutkan di atas perlu diterapkan secara berkesinambungan, agar guru senantiasa melakukan upaya-upaya perbaikan dalam tindakan pengajarannya sehingga akan terjadi peningkatan motivasi dan prestasi belajar siswa.

c. Bagi Siswa

1) Agar siswa selalu antusias dalam KBM, lebih berani mengungkapkan gagasannya, berkomunikasi dan berkerjasama dengan teman kelompoknya, membiasakan aktif dalam segala permasalahan yang ditemui dalam kehidupan sehari-hari, mengaktualisasikan materi yang dipelajari dalam kehidupan sehari-hari, karena itu merupakan jalan untuk mendapatkan motivasi dan prestasi belajar yang lebih baik.

2) Agar siswa lebih meningkatkan motivasi belajar, sebab terbukti bahwa siswa yang memiliki prestasi belajar yang baik adalah siswa yang memiliki motivasi belajar yang tinggi.

2. Perlu dilakukan penelitian lebih lanjut untuk membuktikan pengaruh pendidikan kontekstual dengan teknik Learning Community terhadap motivasi dan prestasi belajar siswa dengan desain eksperimen yang menggunakan kelompok kontrol, sehingga dapat menghasilkan penelitian yang lebih akurat, valid dan reliabel. 


\section{Daftar Rujukan}

Ahmad Rohani,. 2004. Pengelolaan Pengajaran. Jakarta: Rineka Cipta

A.M, Sardiman. 2005. Interaksi dan Motivasi Belajar Mengajar. Jakarta: Raja Grafindo Persada

Arikunto, Suharsimi. 2002. Prosuder Penelitian Suatu Pendekatan Praktek. Jakarta: Rineka

Dimyati dan Mudjiono. 1999. Belajar dan Pembelajaran. Jakarta: Bumi Aksara Hartatik, dkk, 2002.Lembaga Pengabdian Kepada Masyarakat, Malang: Universitas Negeri Malang.

Kasihani, dkk. 2003. Pembelajaran Berbasis CTL. Makalah Disampaikan pada Sarasehan Pendekatan Pembelajaran Kontekstual (CTL) di Fakultas Sastra Universitas Negeri Malang.

Masnur 1987. Dasar-dasar interaksi Belajar Mengajar Mengajar.Malang: Jemmars

Nurhadi, dkk. 2004. Pembelajaran Kontekstual dan Penerapannya Dalam KBK. Malang: Universitas Negeri Malang

MuhibinSyah, 2003. Psikologi Pendidikan Dengan Pendekatan Baru. Bandung: RemajaRosdakarya

Moleong, Lexy J. 2002. Metodologi Penelitian Kualitatif. Bandung: Remaja Rosdakarya.

N.K., Roestiyah. 2001. Strategi Belajar Mengajar. Jakarta: Rineka Cipta

Oemar Hamalik,. 1992. Psikologi Belajar dan Mengajar. Bandung: Sinar Baru

OemarHamalik.2001. Proses Belajar Mengajar.Jakarta: BumiAksara

Purwanto, M. Ngalim. 2000. Psikologi Pendidikan. Bandung: Remaja Rosdakarya

Sidi, Indra Djati. 2003. Menuju Masyarakat Belajar. Jakarta: Paramadina dan Logos

Slameto, 2003. Belajar dan Faktor - faktor Yang Mempengaruhinya. Jakarta: Rineka Cipta.

Slamet. MBS, Life Skill, KBK, CTL, dan salingketerkaitannya, http://pelangi.ditplp.go.id/artikelmb.htm. 
IMPLEMENTASI PEMBELAJARAN SEJARAH DENGAN TEKNIK

KONTEKTUAL COMMUNITY UNTUK MENINGKATKAN MOTIVASI

DAN PRESTASI BELAJAR SISWA KELAS XII/IPS.4 SMAN 1 KERTOSONO NGANJUK

Soedarsono, FX. 2001. Aplikasi Penelitian Tindakan Kelas. Jakarta: Departemen Pendidikan Nasional

Zainal Aqib. 2018. Penelitian Tindakan Kelas. Yogyakarta. Deepublish 
Sawin

106 Annaba : Jurnal Pendidikan Islam 